Revista Arbitrada Interdisciplinaria KOINONIA

Año 2020. Vol V. №2. Especial: Saber y Tecnología Popular Hecho el depósito de Ley: FA2016000010

ISSN: 2542-3088

FUNDACIÓN KOINONIA (F.K). Santa Ana de Coro. Venezuela.

Fabián Segundo Guamán-Quinche; Dalton Euclides Sarango-Guamán; Ángela Edith Guerrero-Pincay

http://dx.doi.org/10.35381/r.k.v5i2.987

\title{
Prevalencia de hemoparásitos en bovino de carne en la Comunidad Cocha del Betano, Ecuador
}

\section{Prevalence of haemoparasites in beef cattle in the Cocha del Betano Community, Ecuador}

Fabián Segundo Guamán-Quinche

fabian1980g@hotmail.com

Escuela Superior Politécnica de Chimborazo, Sede Orellana

Ecuador

Universidad del Zulia

Venezuela

https://orcid.org/0000-0002-9228-2126

Dalton Euclides Sarango-Guamán

daltonsarango@yahoo.com

Escuela Superior Politécnica de Chimborazo, Sede Orellana

Ecuador

https://orcid.org/0000-0002-2890-0882

Ángela Edith Guerrero-Pincay

edith.guerrero@espoch.edu.ec

Escuela Superior Politécnica de Chimborazo, Sede Orellana

Ecuador

https://orcid.org/0000-0002-1028-4428

Recepción: 05 de julio 2020

Revisado: 28 de agosto 2020

Aprobación: 17 de septiembre 2020

Publicación: 01 de octubre 2020 
Revista Arbitrada Interdisciplinaria KOINONIA

Año 2020. Vol V. N’2. Especial: Saber y Tecnología Popular Hecho el depósito de Ley: FA2016000010

ISSN: 2542-3088

FUNDACIÓN KOINONIA (F.K). Santa Ana de Coro. Venezuela.

Fabián Segundo Guamán-Quinche; Dalton Euclides Sarango-Guamán; Ángela Edith Guerrero-Pincay

\title{
RESUMEN
}

El objetivo de la investigación se concentró en analizar la prevalencia de hemoparásitos en bovinos carne en la comunidad del Cocha del Betano, Parroquia Jambelí, Cantón Lago Agrío, Provincia de Sucumbíos, Ecuador. En base al análisis de laboratorio, por frotis sanguíneo por tinción de Giemsa, la finca Ebrón tuvo la mayor incidencia del $23.73 \%$, la finca Betty tuvo una menor incidencia parasitaria del $1.69 \%$, referente a las edades la mayor incidencia corresponde a los animales de 12 a 24 meses y la menor incidencia en animales mayores a 24 meses. Referente al sexo los machos fueron los más afectados con un $52,54 \%$ y las hembras con $47,46 \%$, la prevalencia de la raza mestiza fue del $71,19 \%$, seguido de la raza Brahmán con un $28,81 \%$. Todas las fincas ganaderas investigadas, no llevan registros sanitarios, ni la respectiva identificación de los bovinos por lo que se dificultó la toma de datos.

Descriptores: Ganado; parasitología; enfermedad animal. (Palabras tomadas del Tesauro UNESCO).

\begin{abstract}
The objective of the research focused on analyzing the prevalence of haemoparsites in beef cattle in the Community of Cocha del Betano, Jambelí Parish, Canton Lake Agrío, Sucumbíos Province, Ecuador. Based on laboratory analysis, by blood smear by Giemsa staining, the Ebron farm had the highest incidence of $23.73 \%$; the Betty farm had a lower parasitic incidence of $1.69 \%$, relative to the ages the highest incidence corresponds to animals of 12 to 24 months and the lowest incidence in animals greater than 24 months. Regarding sex males were the most affected with $52.54 \%$ and females with $47.46 \%$, the prevalence of the mixed race was $71.19 \%$, followed by the Brahmin race with $28.81 \%$. All livestock farms investigated do not keep health records, nor the respective identification of cattle making it difficult to take data.
\end{abstract}

Descriptors: Livestock; parasitology; animal diseases. (Words taken from the UNESCO Thesaurus). 


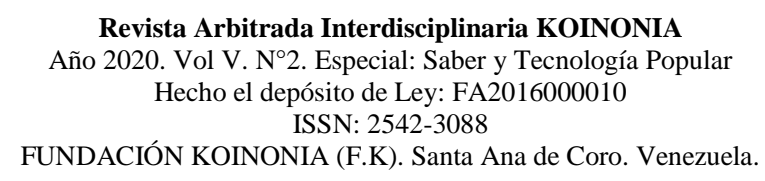

Fabián Segundo Guamán-Quinche; Dalton Euclides Sarango-Guamán; Ángela Edith Guerrero-Pincay

\section{INTRODUCCIÓN}

Las enfermedades parasitarias son una limitante para obtener parámetros aceptables de producción y disminución de recursos económicos para el productor, actualmente en la ganadería de la zona por un descontrol en el cruzamiento de razas existen una mayor susceptibilidad de estas. Son varios los hemoparásitos que afectan a los bovinos, entre los más habituales son: Babesia bovis, B. bigemina y Anaplasma marginale; estos causan infecciones con cursos agudos, subagudos y crónicos, dependiendo del curso clínico, los animales son capaces de producir anticuerpos y generar inmunidad (Instituto Valenciano de Microbiología, IVAMI, 2014)

La producción de bovinos de la Parroquia Jambelí, comunidad del Cocha del Betano, Provincia de Sucumbíos, Ecuador, con frecuencia es afectado por la incidencia elevada de Parasitosis Externa, incidiendo negativamente en la economía de las comunidades de la provincia, por otro lado, muchos animales mueren o experimentan convalecencias prolongadas, con disminución en la producción tanto de carne como de leche. La efectividad de las medidas que se han de aplicar para prevenir y controlar estas enfermedades se relaciona con la educomunicación, y manejo epidemiológico de ciertas enfermedades, sin embargo, los ganaderos, al no contar con asistencia veterinaria especializada (MAGAP, AGROCALIDAD, CISAS y expendedores de productos especializados), así como medicamentos precisos para el caso, las parasitosis se constituyen en una grave amenaza tanto para la salud del animal como humana.

Siendo necesario identificar desde el diagnostico científico, los hemoparásitos con la finalidad de aplicarles el respectivo tratamiento clínico, con lo cual se minimiza el riesgo de muerte en animales, pérdidas económicas, existiendo posibilidad de elevar la productividad de carne y lácteos, redundando en una mejor oferta a la demanda de consumo, garantizando animales saludables y aptos para el consumo humano. Desde lo planteado, el objetivo de la investigación se concentró en analizar la prevalencia de hemoparásitos en bovinos de carne, en la comunidad de la Cocha del Betano, en el cantón Lago Agrío, Provincia de Sucumbíos, Ecuador. 


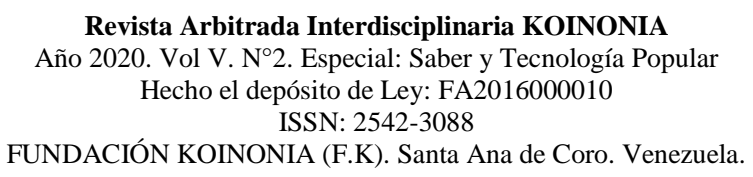

Fabián Segundo Guamán-Quinche; Dalton Euclides Sarango-Guamán; Ángela Edith Guerrero-Pincay

\section{METODO}

El apartado metodológico se desarrolla en función de los siguientes aspectos:

\section{Localización y duración de la investigación}

La investigación se efectuó en la comunidad de la Cocha del Betano, Parroquia de Jambelí, Cantón Lago Agrío, Provincia de Sucumbíos, la comunidad tiene una superficie de 454 hectáreas, conformada por 10 fincas en su totalidad se tomaron las muestras correspondiente a la población total existente de bovinos, tuvo una duración de 60 días, las muestras fueron registradas, conservadas, preparadas y analizadas en el laboratorio básico de la Escuela Superior Politécnica de Chimborazo Sede Orellana, ubicado en la ciudad de Puerto Francisco de Orellana, Provincia de Orellana, Ecuador.

\section{Muestra poblacional}

Las 10 fincas en estudio tenían una población de 132 bovinos, de los cuales se tomaron las muestras el $100 \%$ de la población, sin síntomas aparentes de enfermedad hemolítica, las fincas fueron: Ebron 60; Aldemar 4; Vera 5; Verdesoto 12; Valera 5; Barsuto 2; Alvarado 3; Dos hermanos 17; Catorce hermanos 18 y Castillo 6.

\section{Recogida de muestra}

La toma de muestra, serán acompañadas de un formulario u hoja de campo correspondiente que contendrán información para asegurar su procedencia y trazabilidad, cada recipiente o tubo deberán estar identificadas, todas las muestras deben ser identificadas con letra legible, con marcador de tinta indeleble y con la codificación requerida, se muestrearon animales sanos, la asepsia son muy importantes para la toma de muestras para la seguridad personal del técnico y asistente. Para las muestras serológicas se toma en tubos vacutainers con anticoagulante EDTA 7,2 mg (tubos de tapa lila) de la vena coccígea o caudal, y vena yugular, con la aguja calibre 21G 1/2 camisa (capuchón), después se realizó el frotis en la placa procedimiento 


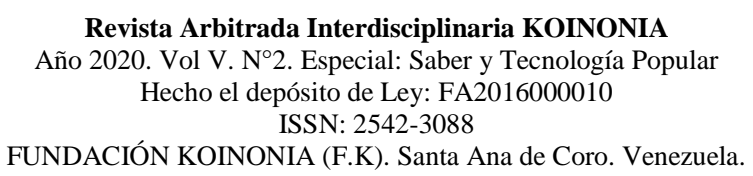

Fabián Segundo Guamán-Quinche; Dalton Euclides Sarango-Guamán; Ángela Edith Guerrero-Pincay

tomado del instructivo de la toma y envío de muestras en animales domésticos (AGROCALIDAD 2019)

Del primer grupo de animales menores de 12 meses de edad se tomaron 16 muestras, que corresponden al 12,12\%; del segundo grupo de 13 meses a 24 meses, 83 muestras con el $70,45 \%$ y del tercer grupo de 25 meses en adelante, 24 muestras que fueron el $17,42 \%$.

\section{Procedimiento}

1. Se procedió a visitar la totalidad de las fincas de la comunidad

2. Nos reunimos con el líder comunal y con los propietarios de las fincas, se dialogó y se sensibilizó a los ganaderos sobre la importancia de realizar la investigación, con la finalidad de establecer la perisología necesaria para obtener las muestras y con los resultados obtenidos, indicar cuál es el tratamiento específico de aquellos bovinos positivos a los hemoparásitarios

3. Se realizó un cronograma de visitas y la respectiva toma de la muestra

4. Por cada muestra se obtuvieron $3 \mathrm{ml}$ de sangre de la vena coccígea media, en caso de los bovinos dóciles, en cambio de bovinos muy nerviosos de la vena yugular externa, en tubos con anticoagulante, que se transportaron en refrigeración para ser analizadas en las instalaciones del laboratorio Básico de la Escuela Superior Politécnica de Chimborazo para el respectivo análisis del cuadro hemático, para el diagnóstico de Babesia y Anaplasma.

\section{Materiales y equipos de campo y laboratorio}

Los materiales de laboratorio empleados en fase de campo fueron: agujas vacutainer calibre $21 \mathrm{G} 1 \times 1 \frac{1}{2}$, tubos vacutainer, de tapa lila K3E EDTA 7,2 $\mathrm{mg}$ de una capacidad de $5 \mathrm{ml}$, algodón, alcohol, yodopovidona, guantes estériles, jabón quirúrgico, lanceta estéril, cooler portátil con geles refrigerantes. Giemsa, metanol, láminas portaobjetos, microscopio. 


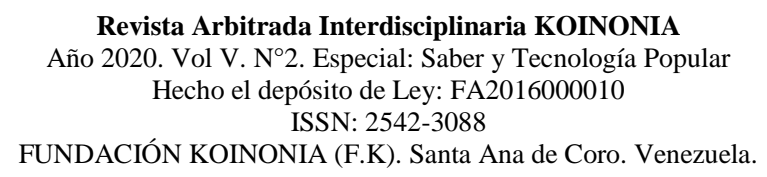

Fabián Segundo Guamán-Quinche; Dalton Euclides Sarango-Guamán; Ángela Edith Guerrero-Pincay

\section{Técnicas de Diagnóstico}

Tinción de Giemsa: El colorante está compuesto de azul de metileno (que tiñe los componentes ácidos como el núcleo y el RNA citoplasmático) y la eosina (que tiñe de rojo los componentes básicos como la hemoglobina); este examen microscópico de frotis sanguíneo con tinción de Giemsa, es la técnica diagnóstica de referencia y el método más común para la identificación de hemoparásitos en animales con infección clínica, esta tinción es capaz de detectar niveles de parasitemia de $0.1 \%$ a $0.2 \%$, es decir detecta niveles mayores a 106 eritrocitos infectados por mililitro de sangre; sin embargo, cuando el animal está en la fase crónica o en el estadio de portador no expresa un elevado nivel de parasitemia el cual permanece con una infección persistente, con un $0.000001 \%-0.1 \%$ de eritrocitos infectados, como para ser detectado por la tinción (Herrera et al., 2008; Bradford, 2010; Corona et al., 2011; ArboledaGarcía, 2019).

Se procedió hacer la dilución del colorante Giemsa al 1×10 (ejemplo, se utiliza $18 \mathrm{ml}$ de agua amortiguadora y $2 \mathrm{ml}$ del colorante; bastarán para 4 frotis, pero si necesita teñir más gradué el volumen si es necesario para teñir más frotis) Los pasos realizados para la Tinción de Giemsa en frotis, se deben fijar primero durante 2-3 minutos con metanol; coloqué los portaobjetos a través de dos varillas de vidrio. Cúbralos con tinción de Giemsa diluida; Déjense reposar 30 minutos; Lave la tinción con agua amortiguada. No intente desprenderla primero y lavarla después ya que así quedaría un depósito de colorante sobre el frotis; Escurra el agua. Coloque los portaobjetos en una gradilla para dejar que se sequen. Póngales en posición inclinada con la capa de sangre teñida vuelta hacia abajo, para proteger del polvo. se dejó secar al aire por un tiempo de 15 minutos, se observó al microscopio frotando a cada frotis el aceite de inmersión y visualizado con lente objetivo 100X (OPS., 1983) 


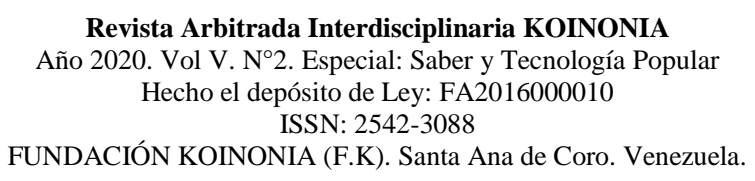

Fabián Segundo Guamán-Quinche; Dalton Euclides Sarango-Guamán; Ángela Edith Guerrero-Pincay

\section{Análisis estadístico}

Se procedió mediante estadística descriptiva a calcular el porcentaje de los animales afectados, según edad, raza, sexo, hacienda, con la finalidad de caracterizar la muestra poblacional.

\section{RESULTADO}

En los resultados generales de las 132 muestras analizadas, 59 fueron positivas a hemoparásitos constituyendo el 44,70\% de la población afectada. El 44,07\% correspondieron Anaplasma marginale, el 33,90 Babesia bigemina y el 22,03 Anaplasma marginale + Babesia bigemina. La raza mestiza fue de mayor prevalencia con el $71,19 \%$, seguido de la raza Brahmán con un $28,81 \%$.

El análisis de laboratorio determino que la finca Ebrón tuvo la mayor incidencia de hemoparásitos 23,73\%, la finca Betty, tuvo menor incidencia parasitaria con un 1,69\%, definiéndose que la mayor incidencia hemoparasitaria corresponde a los animales que tienen una edad de 12 a 24 meses 59,32\%, seguido de animales menores de 12 meses con el $22,03 \%$ y animales mayores de 2 años en adelante con un $18,64 \%$.

En base al sexo de los bovinos los machos tienen una prevalencia más alta con un $52,54 \%$ y las hembras en $47,47 \%$.

Los becerros son más resistentes a la enfermedad y a la infección que los adultos, pero hasta los 3 a 4 meses de edad y es mínimo de 3 a 6 meses. En las razas el hemoparásito más común fue la Anaplasma marginale, seguido de la Babesia bovis, aunque esta última sólo se observó en la raza Brahman.

De acuerdo con la edad, los bovinos entre los 13 a 24 meses fueron los más parasitados los animales mayores de 24 meses fue baja con relación a los otros grupos. En todos los grupos de edades el hemoparásito más prevalente fue la Anaplasma marginale, seguido de la Babesia bigemina, y Anaplasma marginale + Babesia bigemina este último con relación a los otros grupos es bajo. 


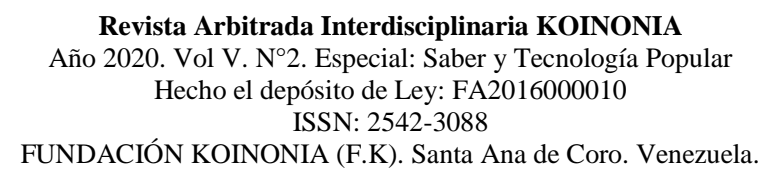

Fabián Segundo Guamán-Quinche; Dalton Euclides Sarango-Guamán; Ángela Edith Guerrero-Pincay

\section{DISCUSIÓN}

La actividad bovina en Ecuador se distribuye por regiones: la zona de Sierra representa el 50,6\%, La Costa y el Oriente con el 36,3 y 13,1\%, respectivamente, del censo nacional, donde predomina el clima cálido y el sistema de doble propósito. (Giselli et al. 2015).

Los parásitos y su transmisión producen pérdida de sangre, que provoca disminución en el peso, anemia y mala calidad de pieles. Por otra parte, estos problemas de salud acarrean daños al productor en su economía. Por estos es necesario contar con un medicamento eficaz contra hemoparásitario (Zahid, et al., 2006).

Las zonas del trópico y subtrópico proveen condiciones ambientales favorables para la multiplicación de artrópodos vectores de enfermedades, principalmente garrapatas y moscas picadoras (Benavides, 2001), lo que brinda condiciones ecológicas para la presencia de hemoparásitos del ganado

Las enfermedades transmitidas por la garrapata (Boophilus) microplus es una importante causa que limita la productividad del ganado bovino. En general los estudios epidemiológicos han demostrado que estos patógenos frecuentemente ocurren en el ganado bovino y su vector la garrapata. La garrapata (Boophilus) microplus es el vector de la Babesia bovis, B. bigemina y Anaplasma marginale. Estas enfermedades son endémicas en las zonas tropicales y semitropicales. La Babesia bovis es la especie más patógena que $B$. bigemina, y son los agentes causales de la babesiosis bovina; $y$ el Anaplasma marginale es el agente causal de la anaplasmosis bovina.

Los síntomas generados por los hemoparásitos muestran similitudes y cooperan características de su transmisión y epidemiologías (Benavides et al., 2017). Por otro lado, la anaplasmosis se caracteriza por la alta destrucción de las células infectadas, produciendo depresión, debilidad, pérdida de peso, ictericia, fiebre y anemia progresiva, disminución en la producción de leche y muerte (Rymaszewska y Grenda, 2008).

Por lo general, los animales jóvenes son menos susceptibles a los efectos clínicos de la enfermedad y los brotes en animales adultos ocurren por movilización de animales susceptibles a regiones donde está la enfermedad, o por la ruptura del equilibrio 


\section{Revista Arbitrada Interdisciplinaria KOINONIA \\ Año 2020. Vol V. N². Especial: Saber y Tecnología Popular Hecho el depósito de Ley: FA2016000010 \\ ISSN: 2542-3088 \\ FUNDACIÓN KOINONIA (F.K). Santa Ana de Coro. Venezuela.}

Fabián Segundo Guamán-Quinche; Dalton Euclides Sarango-Guamán; Ángela Edith Guerrero-Pincay

epidemiológico (Benavides 2002).

En zonas donde el ecosistema es altamente favorable para la garrapata (por componentes de alta temperatura y humedad), los ganaderos usualmente tienden a utilizar animales con diversos grados de mestizaje con la raza Cebú, por su mayor resistencia a la garrapata, pero también por el estrés calórico. Allí generalmente ocurre estabilidad enzoótica de hemoparásitos con circulación del organismo en los animales adultos, que son portadores subclínicos, y por la escasa ocurrencia de casos de enfermedad clínica (Benavides 2002).

Estas enfermedades hematozoarias influyen en los programas de mejoramiento bovino en el trópico, por las restricciones en el uso de razas Bos taurus, con el objetivo de aumentar la productividad de las razas B. indicus, siendo las B. taurus más susceptibles a infestaciones por ectoparásitos, protozoarios y rickettsias (González \& Meléndez, 2007)

Se conoce que ganados B., indicus son más resistentes a los ectoparásitos que los B. taurus (Bianchin et al. 2007) y con el cruzamiento de estos dos grupos, se produce un mestizaje, que permite el incremento de los índices productivos, debido al vigor hibrido o heterosis, generado en el cruce y mayor grado de resistencia a las condiciones tropicales, frente al B. taurus (Frisch et al. 2000; Silva et al. 2007; Oliveira et al. 2009).

\section{CONCLUSIÓN}

Enfermedades, que siempre estarán presentes por factores que puedes ser controlados, pero lamentablemente no se ejecutan, debido a falta de una edocomunicaciín en la parte de manejo, uso de fármacos, en las fincas de la comunidad hay mayor prevalencia de Anaplasma marginale, Babesia bigemina y Babesia bigemina + Anaplasma marginale, fueron identificadas mediante análisis de laboratorio, los ganaderos.

Los animales de 13 meses a 24 meses fueron los más afectados con un 59,32\% y los animales mayores a 24 meses obtuvieron un 18,64 \%, mientras que la raza mestiza su prevalencia es de $71,19 \%$, seguido de la raza Brahmán con un $28,81 \%$. De todas las 


\section{Revista Arbitrada Interdisciplinaria KOINONIA \\ Año 2020. Vol V. N². Especial: Saber y Tecnología Popular Hecho el depósito de Ley: FA2016000010 \\ ISSN: 2542-3088 \\ FUNDACIÓN KOINONIA (F.K). Santa Ana de Coro. Venezuela.}

Fabián Segundo Guamán-Quinche; Dalton Euclides Sarango-Guamán; Ángela Edith Guerrero-Pincay

explotaciones atendidas, no lleva registros, ni identificados lo que se dificultó la toma de datos. Las fincas en las que se realizó la investigación su altura no es relevante porque era en promedio de 10 metros y esto no fue un factor definitivo en la presencia de hemoparásitos.

Esta mayor frecuencia de Anaplasma sp., en el actual estudio, se puede deber a que el muestreo se efectuó en la época de variables de precipitación, donde hay mayor infestación de garrapatas y las condiciones ambientales disminuyen la disponibilidad de forrajes, situaciones que conducen a estrés, produciendo un aumento de infecciones por hematozoarios. Otras causas, como picaduras de moscas y factores iatrogénicos, como el no uso de agujas estériles por animal y el no cambio de guantes en chequeos reproductivos, han sido reportadas como causas de hematozoarios (Souza et al. 2013), variables que no fueron evaluadas en el presente estudio

\section{FINANCIAMIENTO}

No monetario

\section{AGRADECIMIENTO}

A los propietarios de las fincas, al líder comunal de la comunidad Cocha del Betano. A la Escuela Superior Politécnica, sede Orellana; por prestar los equipos para el análisis de las placas. A la Universidad de Zulia, por su repositorio de investigación. 
Revista Arbitrada Interdisciplinaria KOINONIA

Año 2020. Vol V. ํ⒉ Especial: Saber y Tecnología Popular Hecho el depósito de Ley: FA2016000010

ISSN: 2542-3088

FUNDACIÓN KOINONIA (F.K). Santa Ana de Coro. Venezuela.

Fabián Segundo Guamán-Quinche; Dalton Euclides Sarango-Guamán; Ángela Edith Guerrero-Pincay

\section{REFERENCIAS CONSULTADAS}

AGROCALIDAD. (2019). Instructivo INT/DA/019. Toma y envío de muestras en animales domésticos. [Instructions INT/DA/019. Taking and sending simples in domestic animals]. Recuperado de https://n9.cl/2mnv

Arboleda-García, M. (2019). Diagnóstico molecular y prevalencia de Babesia spp. Mediante PCR-RFLP en ganado bovino en la provincia de Manabí-Ecuador. Trabajo de grado (p. 81). Manabí-Ecuador. [Molecular diagnosis and prevalence of Babesia spp. Through PCR-RFLP in cattle in the province of Manabí-Ecuador]: Universidad de Fuerzas Armadas innovación para la ciencia ESPE. Recuperado de https://n9.cl/xcyb

Benavides, E. (2002). Epidemiología y control de los hematozoarios y parásitos tisulares que afectan al ganado. [Epidemiology and control of hematozoa and tissue parasites that affect cattle] Carta Fedegan, 72 (Anexo coleccionable 9):112-134.

Benavides, E., \& Romero A. (2001). Consideraciones para el control integral de parásitos externos del ganado. [Considerations for the comprehensive control of external parasites in livetock] Carta Fedegan. 2001;70 (anexo coleccionable 7):64-86.

Benavides-Ortiz, E, \& Polanco-Palencia, N. (2017). Epidemiología de hemoparásitos y endoparásitos en bovinos de zonas de reconversión ganadera en La Macarena (Meta, Colombia). [Epidemiology of hemoparasites and endoparasites in bovines from livestock conversion areas in La Macarena (Meta, Colombia)]. Revista de Medicina Veterinaria, (34, Suppl. 1), 115-136. https://dx.doi.org/10.19052/mv.4260

Bradford, S. (2010). Medicina interna de grandes animales. [Large Animal Internal Medicine] (cuarta ed.). España, Barcelona: ELSEVIER.

Corona, B., \& Martínez, S. (2011). Detección de Anaplasma marginale en bovinos, mediante la amplificación por PCR del gen msp5. [Detection of Anaplasma marginale in bovine, using the msp5 gene amplification by PCR]. Rev Salud Anim, 33(1), 24-31.

Frisch, J., O'Neill, C., \& Kelly. (2000). Using genetics to control cattle parasites: the Rockhampton experience. Ind. J. Parasitol. 30:253-264. 


\section{Revista Arbitrada Interdisciplinaria KOINONIA \\ Año 2020. Vol V. N’2. Especial: Saber y Tecnología Popular Hecho el depósito de Ley: FA2016000010 \\ ISSN: 2542-3088 \\ FUNDACIÓN KOINONIA (F.K). Santa Ana de Coro. Venezuela.}

Fabián Segundo Guamán-Quinche; Dalton Euclides Sarango-Guamán; Ángela Edith Guerrero-Pincay

Giselli, Y.; García, A.; Rivas, J.; Perea, J.; Angón, E. y De Pablos, C. (2015). Caracterización socioeconómica y productiva de las granjas de doble propósito orientadas a la producción de leche en una región tropical de Ecuador. Caso de la provincia de Manabí. [Socio-economic and productive characterization of dualpurpose farms aimed at milk production in a tropical región of Ecuador. Case of the province of Manabi]; Revista Científica FCV-LUZ, 25(4); 330-337.

González, J.R., \& Meléndez, R.D. (2007). Seroprevalencia de la tripanosomiasis y anaplasmosis bovina en el municipio Juan José Mora del Estado Carabobo, Venezuela, mediante la técnica de Elisa. [Seroprevalence of tripanosomiasis and bovine anaplasmosis in the Juan José Mora municipality of Carabobo State, Venezuela, using the Elisa technique]; Rev. Cient. (Venezuela). 17(5):7-10.

Herrera, M., Soto, Á., Urrego, V., Rivera, G., Zapata, M., \& Ríos, L. (2008). Frecuencia de hemoparasitos en bovinos del bajo Cauca y alto de San Jorge, 2000-2005. [Frequency of hemoparasites of bovines from Cauca and San Jorge Rivers, 2000-2005]; Rev M.V.Z de Córdoba, 13(3), 1486-1494.

IVAMI. (2014). Babesiosis. Recuperado de https://n9.cl/gom0

Oliveira, M., Alencar, M., Chagas, A., Giglioti, R., \& Oliveira, N. (2009). Gastrointestinal nematode infection in beef cattle of different genetic groups in Brazil. Vet. Parasitol. 166:249-254.

OPS. (1983). Manual de Técnicas Básicas para un Laboratorio de Salud. [Manual of Basic Techniques for a Health Laboratory]. Publicación Científica № 439 ISBN 92 41541458 . Recuperado de https://n9.cl/jniij

Rymaszewska A. \& Grenda S. (2008): Bacteria of the genus Anaplasma characteristics of Anaplasma and their vectors: a review. Veterinarni Medicina, 53: 573-584.

Silva, A.M., Alencar, M.M., Regitano, A., Oliveira, S., \& Barioni, W. (2007). Artificial infesta- Artificial infestation of Boophilus microplus in beef cattle heifers of four genetic groups. Gen. Mol. Biol.30:1150-1155.

Souza, F., Braga, J.V., Lidiany, V., Carvalho, C., Costa, E.A., Múcio, F., Ribeiro, V., Antos, R.L., \& Silva, M. (2013). Babesiosis and anaplasmosis in dairy cattle in Northeastern Brazil. Pesq. Vet. Bras. 33(9):1057- 1061. 
Revista Arbitrada Interdisciplinaria KOINONIA

Año 2020. Vol V. №2. Especial: Saber y Tecnología Popular Hecho el depósito de Ley: FA2016000010

ISSN: 2542-3088

FUNDACIÓN KOINONIA (F.K). Santa Ana de Coro. Venezuela.

Fabián Segundo Guamán-Quinche; Dalton Euclides Sarango-Guamán; Ángela Edith Guerrero-Pincay

Zahid, I. R., Song-hua, H., Wan-jun, Ch., Abdullah, A., \& Chen-wen, X. (2006). Importancia de las garrapatas y su control químico e inmunológico en el ganado. [Importance of ticks and their chemical and immunological control in cattle]. Revista de CIENCIAS de la Universidad de Zhejiang B7(11), 912-21.

\footnotetext{
C2020 por los autores. Este artículo es de acceso abierto y distribuido según los términos y condiciones de la licencia Creative Commons Atribución-NoComercial-Compartirlgual 4.0 Internacional (CC BY-NC-SA 4.0) (https://creativecommons.org/licenses/by-nc-sa/4.0/).
} 